\title{
Prevalence of Diagnosed Obstructive Sleep Apnea in the United States 2013-2016: Insured Patients Actively Seeking
} Care

\section{Gregory P. Hess ${ }^{1}$; Christine Won²; Joanna M-H. Suomi ${ }^{3}$; Morgan Bron ${ }^{4}$; John Acquavella 5}

${ }^{1}$ University of Pennsylvania

${ }^{2}$ Yale University School of Medicine

${ }^{3}$ formerly Jazz Pharmaceuticals

${ }^{4}$ Independent

${ }^{5}$ Aarhus University

DDOI: https://doi.org/10.15520/jcmro.v3i06.301

Accepted 15-06-2020; Received 25-05-2020; Publish Online 16-06-2020

Reviewed By:

Dr. Songul B. Diler

Department:

Reviewer/CMRO

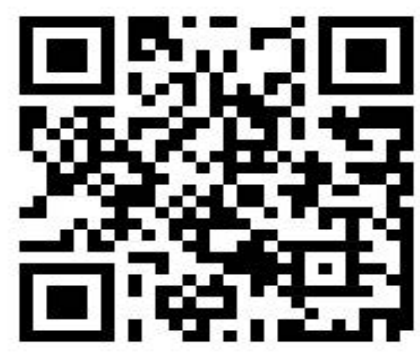

\section{Abstract:}

Background: The prevalence of obstructive sleep apnea (OSA) has not been assessed within the United States (US) in over a decade.

Objectives: From 2013 to 2016, we calculated annual 2-year limited duration prevalence of diagnosed OSA in a large ( 66 million), geographically diverse insured population We evaluated trends by age and sex; and assessed positive airway pressure (PAP) use and excessive sleepiness (hypersomnia diagnosis, or prescriptions for stimulant or wakepromoting agent [WPA]).

Methods: Overall and age/sex specific prevalence per 100 insured persons was calculated on an annual basis. The cohort was defined to include those with medical and pharmacy claims activity. To mitigate rule-out diagnoses, cases had to have $\geq 2$ medical claims for OSA within a 6-month period. Overall annual prevalences were directly standardized to the US population using 2016 US age and sex Census weights.

Results: Annual age/sex adjusted prevalence of OSA increased from $2.4 \%$ in 2013 to $3.4 \%$ in 2016. OSA patients had a mean age of 58 years and there was a $\approx 2: 1$ male: female prevalence ratio. OSA patients with PAP claims increased from $42.2 \%$ to $44.1 \%$ over the study period. Excessive sleepiness (hypersomnia or stimulant/WPA prescriptions) for patients with or without PAP use both declined by $\approx 4 \%-5 \%$.

Conclusions: Diagnosed OSA prevalence and PAP use among insured members with claims activity increased during 2013-2016 while clinical markers of excessive sleepiness declined. Males had a much higher prevalence of OSA than females.

Key words: Obstructive sleep, apnea Prevalence, Positive airway pressure, Stimulants, Wake-promoting agents 


\section{Introduction:}

Obstructive sleep apnea (OSA) is a chronic sleep disorder, closely linked with increasing age and obesity. As the population of the United States (US) ages and obesity becomes more common, awareness has increased, with emphasis on better screening for and diagnosis of this disease 1,2,3. Nonetheless, OSA is an insidious and underrecognized disease 4,5, Additionally, it carries significant morbidity 6 including associations with acute coronary syndromes 7 , atrial fibrillation 8 , hypertension 9, glaucoma 10 stroke 11 , sickle cell anemia 12, and other diseases. Given the significance and often unrecognized nature of this disease, estimates of prevalence and related trends are important for patients, healthcare providers, and insurers.

Relatively recent publications estimate varying prevalences. A review from 2008 estimated a 2$5 \%$ prevalence worldwide in women and a $4-7 \%$ prevalence worldwide in men, using data from studies between 1993-2004 13. The 2012 Wisconsin Sleep Cohort Study estimated a $26 \%$ prevalence of mild to severe sleep disordered breathing among 30- to 70-year-olds during 2007-2010. 14 A population-based study of 2,121 people in Switzerland covering 2009-2013 found an OSA prevalence of $23.4 \%$ in women and $49.7 \%$ in men. $15 \mathrm{~A}$ systematic review of 24 studies assessing OSA prevalence in different areas of the world (including North America, Europe, and Asia) from the 1980s to the 2010s, found the reported prevalence in the general adult population ranged from $6 \%-17 \%$, and as high as $49 \%$ in elderly populations. 16

Given the increasing prevalence of risk factors for OSA in the US population, its significant morbidity, and often unrecognized nature, a more current evaluation of the US national prevalence is warranted. The aim of this study is to estimate the diagnosed prevalence of patients with OSA actively seeking care within a 2 -year window in a large, geographically diverse, US-insured population weighted to the 2016 US Census population. Subgroup analysis of select sleeprelated disorders and treatments was also conducted. To our knowledge this is the largest population studied to date, which allows for very statistically precise analyses (viz. very narrow $95 \%$ confidence intervals [CIs]) for patient subgroups by age, sex, and type of insurance, along with descriptive analyses of select OSA treatment subgroups.

\section{Methods:}

\section{Design, Data Source, Search Strategy, and Objectives:}

We conducted a retrospective cohort study using a nationwide claims database (Symphony Health), which contains patient-level medical and pharmacy claims. The claims are a 'convenience' sample collected routinely as part of the real-world administration and reimbursement processes for patients' healthcare. The medical claims comprise practitioners' standardized professional claims (Form 1500), which includes dates of service, International Classification of Diseases (ICD) 9 and/or 10 code diagnoses, Healthcare Common Procedure Coding System (HCPCS), and Common Procedural Taxonomy (CPT) procedures and treatments for in-patient, ambulatory and outpatient care for approximately $50 \%$ of all annual visits in the US. The pharmacy claims are comprised of National Council for Prescription Drug Program 5.1- format prescription claims aggregated from multiple sources including data clearinghouses, retail pharmacies, and prescription benefit managers for approximately $80 \%$ of US retail pharmacy transactions. Individual claim records included the dates of given pharmacy fills with National Drug Code (NDC) identifying agents and dosage. The database includes more than 220 million unique patients with pharmacy claims and more than 150 million patients with medical claims, including patients from all 50 states and for all payer types, including cashpaying pharmacy patients. Medical encounters include both ambulatory and hospital practitioner claims. Medicare patients in the database are largely enrolled in Medicare Advantage plans and/or supplemental Medicare plans. Claims are linked longitudinally at the patient level through a Health Insurance Portability and Accountability 
(HIPAA)-compliant, unique, synthetic identifier that is permanent for each patient. Claims between January 1, 2013 and December 31, 2016 were assessed.

\section{Objectives:}

The primary objective was to calculate the annual 2-year limited duration prevalence of OSA per 100 eligible insured persons during the period 20132016, and to evaluate trends over that study period. Secondary objectives included analysis of prevalence by age, sex, and payer-type subgroups; and descriptive analyses of select OSA treatment subgroups. Compared with complete prevalence (all past and current cases who are still alive in the eligible population), this limited-duration prevalence focuses on patients who are diagnosed and actively using medical and pharmacy services.

\section{Cohort and Case Definitions:}

To ensure data capture, the prevalence cohort (denominator) included patients with any (a) $\geq 1$ private practitioner claim and $\geq 1$ pharmacy claim at least 12 months before the start of the yearly prevalence calculation; and (b) $\geq 1$ private practitioner claim and $\geq 1$ pharmacy claim at least 12 months after the start of the year; and (c) sex specified as male or female; and (d) a valid date of birth. Cases (numerator) were patients in the prevalence cohort with $\geq 2$ claims within 6 months with a diagnosis of OSA. 17,18,19 This case definition provides 2-year limited-duration prevalence for each calendar year during the 20132016 study period.

Patient claims in the eligible cohort were queried using the ICD 9 and/or 10 codes for OSA, hypersomnia, and other diagnoses of interest, the HCPCS codes for OSA treatments, and the NDC directory codes (in NDC11 format) for wakepromoting agents (WPA)/stimulant prescription therapies. Please see the online Supplemental Appendix for a list of codes.

Data Extraction, Synthesis of Results, and Analysis:

Annual prevalence was calculated within the eligible study population and standardized to the 2016 US census population. The crude age- and sex-specific prevalence in the dataset was calculated by dividing the total number of new and existing cases in each stratum by the total number of persons in the stratum for the calendar year. The total prevalence in each calendar year was then age- and sex-adjusted by summing the products of age- and sex-specific prevalences and the proportions for those subgroups in 2016 Census estimates. This weighting ensures that trends in annual prevalence are not influenced by changes in the age or sex distribution of the overall eligible population, and results in prevalence estimates for the insured population adjusted to the US Census. Lastly, prevalence was extrapolated to the US population by summing the products of age- and sex-specific 2016 prevalence in the study population and the relevant age/sex specific population counts from the 2016 Census. Prevalences and their 95\% CIs are expressed as percentages per 100 persons. The 95\% CI was calculated as: prevalence $\pm 1.96(S E)$. The SE (standard error) was estimated to be the square root of $[\mathrm{p}(1-\mathrm{p}) / \mathrm{n}]$, where $\mathrm{p}$ equals the prevalence and $\mathrm{n}$ is the number of cases in the prevalence calculation. 20

Patient subgroups based on age, sex, and payer type were analyzed for the calendar year 2016. Age categories included <18, 18-24, 25-34, 35-44, $45-54,55-64$, and $\geq 65$ years. The predominant payer type was categorized hierarchically as Medicare, Medicaid, commercial (third-party, non-governmental payers), and all other payers (e.g. Tricare military, etc.). Four OSA treatment subgroups were evaluated: (1) patients with OSA and evidence of positive airway pressure (PAP) use; (2) patients with OSA, PAP use, and excessive sleepiness (for the purposes of this study, excessive sleepiness was defined as hypersomnia diagnosis or use of simulants/WPAs); (3) patients with OSA, no PAP use, and excessive sleepiness, and (4) patients with OSA and no PAP use. Age and sex subgroup analyses were conducted for diagnostic tests and treatment information for the calendar year 2016. Data management and statistical analyses utilized SAS (Statistical Analysis Software) software, version 9.4 (SAS Institute Inc., Cary, NC). 


\section{Results:}

\section{Eligible Population:}

The eligible prevalence cohort ranged annually between approximately 62.9 and 67.5 million patients. From year-to-year, approximately $60 \%$ of the eligible population was female, $\geq 27 \%$ were aged $\geq 65$ years, the majority $(\geq 63 \%)$ had commercial insurance, and $40 \%$ were from the Southern census region; the largest region in the US (Table 1).

Table 1. Eligible Population Table 1 presents the annual eligible population from the database, from 2013 to 2016.

\begin{tabular}{|c|c|c|c|c|c|c|c|c|}
\hline \multirow{2}{*}{$\begin{array}{c}\text { Eligible Database Population } \\
\text { Total } \\
\end{array}$} & \multicolumn{2}{|l|}{2013} & \multicolumn{2}{|l|}{2014} & \multicolumn{2}{|l|}{2015} & \multicolumn{2}{|l|}{2016} \\
\hline & $62,895,565$ & & $66,446,545$ & & $67,519,490$ & & $66,060,231$ & \\
\hline Males, N (\%) & $24,835,605$ & $39 \%$ & $26,348,132$ & $40 \%$ & $26,737,490$ & $40 \%$ & $26,126,600$ & $40 \%$ \\
\hline Females, $\mathbf{N}(\%)$ & $38,059,960$ & $61 \%$ & $40,098,413$ & $60 \%$ & $40,782,000$ & $60 \%$ & $39,933,631$ & $60 \%$ \\
\hline \multicolumn{9}{|l|}{ Age - N (\%) } \\
\hline$\leq 14$ years & $7,846,297$ & $12 \%$ & $8,057,169$ & $12 \%$ & $7,912,383$ & $12 \%$ & $7,478,977$ & $11 \%$ \\
\hline 15 - 17 years & $1,686,640$ & $3 \%$ & $1,777,561$ & $3 \%$ & $1,762,905$ & $3 \%$ & $1,678,652$ & $3 \%$ \\
\hline 18 - 24 years & $4,061,100$ & $6 \%$ & $4,234,132$ & $6 \%$ & $4,265,067$ & $6 \%$ & $4,117,463$ & $6 \%$ \\
\hline 25 - 34 years & $5,564,915$ & $9 \%$ & $5,862,189$ & $9 \%$ & $6,115,502$ & $9 \%$ & $6,026,099$ & $9 \%$ \\
\hline 35 - 44 years & $6,763,262$ & $11 \%$ & $6,976,581$ & $10 \%$ & $7,101,784$ & $11 \%$ & $6,980,485$ & $11 \%$ \\
\hline 45 - 54 years & $9,077,937$ & $14 \%$ & $9,441,987$ & $14 \%$ & $9,571,509$ & $14 \%$ & $9,203,704$ & $14 \%$ \\
\hline 55 - 64 years & $10,691,462$ & $17 \%$ & $11,428,472$ & $17 \%$ & $11,847,662$ & $18 \%$ & $11,708,051$ & $18 \%$ \\
\hline$\geq 65$ years & $17,203,952$ & $27 \%$ & $18,668,454$ & $28 \%$ & $18,942,678$ & $28 \%$ & $18,866,800$ & $29 \%$ \\
\hline \multicolumn{9}{|l|}{ Insurance type - N (\%) } \\
\hline Commercial & $41,169,585$ & $65 \%$ & $42,604,426$ & $64 \%$ & $42,618,908$ & $63 \%$ & $41,388,022$ & $63 \%$ \\
\hline Medicare & $13,768,889$ & $22 \%$ & $14,906,183$ & $22 \%$ & $14,990,366$ & $22 \%$ & $14,637,684$ & $22 \%$ \\
\hline Medicaid & $6,974,455$ & $11 \%$ & $7,996,607$ & $12 \%$ & $9,004,328$ & $13 \%$ & $9,159,884$ & $14 \%$ \\
\hline All Other & 982,636 & $2 \%$ & 939,329 & $1 \%$ & 905,888 & $1 \%$ & 874,641 & $1 \%$ \\
\hline \multicolumn{9}{|l|}{ Census Region - N (\%) } \\
\hline Northeast & $14,997,269$ & $24 \%$ & $16,105,104$ & $24 \%$ & $16,093,047$ & $24 \%$ & $15,351,246$ & $23 \%$ \\
\hline Midwest & $14,567,318$ & $23 \%$ & $15,303,816$ & $23 \%$ & $15,964,741$ & $24 \%$ & $16,075,636$ & $24 \%$ \\
\hline South & $25,158,186$ & $40 \%$ & $26,477,731$ & $40 \%$ & $26,979,188$ & $40 \%$ & $26,304,636$ & $40 \%$ \\
\hline West & $8,172,792$ & $13 \%$ & $8,559,894$ & $13 \%$ & $8,482,514$ & $13 \%$ & $8,328,713$ & $13 \%$ \\
\hline
\end{tabular}




\section{Prevalence of OSA:}

The unadjusted overall prevalence of diagnosed OSA in the insured population increased annually from $2.7 \%$ in 2013 to $3.9 \%$ in 2016, with an annualized mean of 3.2\% (Table 2).

Table 2. US Population Estimates: Patients with OSA, PAP Use and Excessive Sleepiness from 2013 to 2016.

\begin{tabular}{|c|c|c|c|c|c|}
\hline & & \multicolumn{4}{|c|}{ YEAR } \\
\hline & & 2013 & 2014 & 2015 & 2016 \\
\hline & & N or \% $(95 \% \mathrm{CI})$ & $\mathrm{N}$ or $\%(95 \% \mathrm{CI})$ & $\mathrm{N}$ or $\%(95 \% \mathrm{CI})$ & $\mathrm{N}$ or $\%(95 \% \mathrm{CI})$ \\
\hline \multirow[t]{2}{*}{ OSA } & Crude Prevalence & $\begin{array}{c}2.7 \% \\
(2.7 \%-2.7 \%)\end{array}$ & $\begin{array}{c}3.0 \% \\
(3.0 \%-3.0 \%)\end{array}$ & $\begin{array}{c}3.4 \% \\
(3.4 \%-3.4 \%)\end{array}$ & $\begin{array}{c}3.9 \% \\
(3.9 \%-3.9 \%)\end{array}$ \\
\hline & Age \& Sex Adjusted & $2.4 \%$ & $2.6 \%$ & $3.0 \%$ & $3.4 \%$ \\
\hline \multirow{2}{*}{$\begin{array}{l}\text { OSA and } \\
\text { PAP }\end{array}$} & Patients with OSA, $\%$ & $\begin{array}{c}42.2 \% \\
(42.1 \%-42.3 \%)\end{array}$ & $\begin{array}{c}41.6 \% \\
(41.6 \%-41.7 \%)\end{array}$ & $\begin{array}{c}43.2 \% \\
(43.1 \%-43.3 \%)\end{array}$ & $\begin{array}{c}44.1 \% \\
(44.1 \%-44.2 \%)\end{array}$ \\
\hline & US estimate, $\mathrm{N}$ & $3,317,479$ & $3,637,994$ & $4,293,993$ & $5,093,895$ \\
\hline \multirow{4}{*}{$\begin{array}{c}\text { OSA and PAP } \\
\text { and Evidence } \\
\text { of Excessive } \\
\text { Sleepiness }\end{array}$} & $\begin{array}{c}\text { Patients with OSA with } \\
\text { PAP, } \%\end{array}$ & $\begin{array}{c}20.9 \% \\
(20.8 \%-21.0 \%)\end{array}$ & $\begin{array}{c}19.5 \% \\
(19.4 \%-19.6 \%)\end{array}$ & $\begin{array}{c}18.2 \% \\
(18.1 \%-18.2 \%)\end{array}$ & $\begin{array}{c}15.8 \% \\
(15.7 \%-15.8 \%)\end{array}$ \\
\hline & $\begin{array}{l}\% \text { with } \geq 1 \mathrm{Dx} \text { of } \\
\text { Hypersomnia* }\end{array}$ & $\begin{array}{c}16.3 \% \\
(16.2 \%-16.4 \%)\end{array}$ & $\begin{array}{c}15.0 \% \\
(15.0 \%-15.1 \%)\end{array}$ & $\begin{array}{c}13.7 \% \\
(13.6 \%-13.7 \%)\end{array}$ & $\begin{array}{c}11.1 \% \\
(11.1 \%-11.2 \%)\end{array}$ \\
\hline & $\begin{array}{c}\% \text { with } \geq 1 \text { dispensed } \mathrm{Rx} \\
\text { stimulant/WPA* }\end{array}$ & $\begin{array}{c}5.9 \% \\
(5.9 \%-6.0 \%)\end{array}$ & $\begin{array}{c}5.7 \% \\
(5.7 \%-5.8 \%)\end{array}$ & $\begin{array}{c}5.7 \% \\
(5.6 \%-5.7 \%)\end{array}$ & $\begin{array}{c}5.6 \% \\
(5.6 \%-5.7 \%)\end{array}$ \\
\hline & US estimate, $\mathrm{N}$ & 691,977 & 709,525 & 779,948 & 803,490 \\
\hline \multirow{2}{*}{$\begin{array}{l}\text { OSA and no } \\
\text { PAP }\end{array}$} & Patients with OSA, $\%$ & $\begin{array}{c}57.8 \% \\
(57.7 \%-57.9 \%)\end{array}$ & $\begin{array}{c}58.4 \% \\
(58.3 \%-58.4 \%)\end{array}$ & $\begin{array}{c}56.8 \% \\
(56.7 \%-56.9 \%)\end{array}$ & $\begin{array}{c}55.9 \% \\
(55.8 \%-55.9 \%)\end{array}$ \\
\hline & US estimate, $\mathrm{N}$ & $4,543,524$ & $5,099,992$ & $5,646,986$ & $6,449,818$ \\
\hline \multirow{4}{*}{$\begin{array}{l}\text { OSA, and } \\
\text { NO PAP, } \\
\text { and (BUT) } \\
\text { Evidence of } \\
\text { Excessive } \\
\text { Sleepiness }\end{array}$} & Patients with OSA*, \% & $\begin{array}{c}18.7 \% \\
(18.6 \%-18.8 \%)\end{array}$ & $\begin{array}{c}17.3 \% \\
(17.2 \%-17.3 \%)\end{array}$ & $\begin{array}{c}16.0 \% \\
(16.0 \%-16.1 \%)\end{array}$ & $\begin{array}{c}14.1 \% \\
(14.1 \%-14.2 \%)\end{array}$ \\
\hline & $\begin{array}{l}\% \text { with } \geq 1 \text { Dx of } \\
\text { Hypersomnia }\end{array}$ & $\begin{array}{c}14.1 \% \\
(14.1 \%-14.2 \%)\end{array}$ & $\begin{array}{c}12.9 \% \\
(12.9 \%-13.0 \%)\end{array}$ & $\begin{array}{c}11.7 \% \\
(11.7 \%-11.8 \%)\end{array}$ & $\begin{array}{c}9.8 \% \\
(9.8 \%-9.9 \%)\end{array}$ \\
\hline & $\begin{array}{c}\% \text { with } \geq 1 \text { dispensed } \mathrm{Rx} \\
\text { stimulant/WPA }\end{array}$ & $\begin{array}{c}6.2 \% \\
(6.1 \%-6.2 \%)\end{array}$ & $\begin{array}{c}5.8 \% \\
(5.8 \%-5.9 \%)\end{array}$ & $\begin{array}{c}5.6 \% \\
(5.6 \%-5.7 \%)\end{array}$ & $\begin{array}{c}5.5 \% \\
(5.5 \%-5.6 \%)\end{array}$ \\
\hline & US estimate, $\mathrm{N}$ & 848,529 & 880,508 & 903,955 & 912,447 \\
\hline
\end{tabular}

Abbreviations: CI, confidence interval; PAP, positive airway pressure; Dx, diagnosis; OSA, obstructive sleep apnea; $R x$, prescription; US, United States; WPA, wake-promoting agent.

There was an approximate 2:1 male: female ratio in OSA prevalence with a mean age of 58. The majority of patients had commercial insurance. The highest age-specific prevalences were seen in males ages $45-54$ years at $9.0 \%$ and in females ages 55-64 years at $4.9 \%$. The male: female ratio peaked in early adulthood and then attenuated, consistent with an earlier age of onset as well as higher prevalence483 for men. (Figure 1). 
Figure 1. Prevalence of Obstructive Sleep Apnea in the United States in 2016 by Age and Sex.

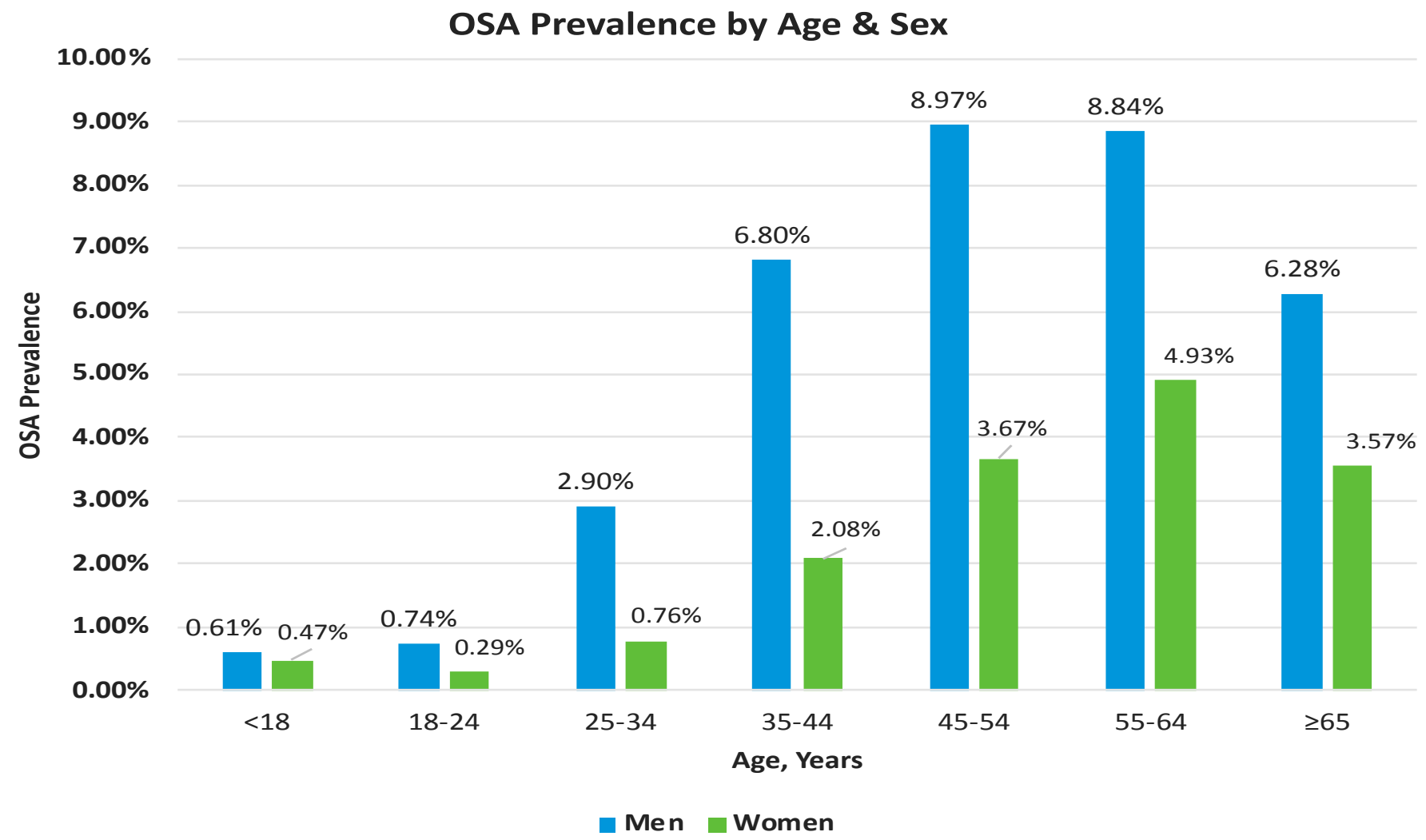

OSA prevalence was generally highest for males insured by commercial payers, while females were most often insured by Medicare (Table 3 and Table 4).

Table 3. Patient Characteristics by OSA Overall and Treatment Type in 2016.

Demographics, medical treatments, and diagnostic tests in patients with OSA overall, by treatment type, and by subgroups of age, sex, and region for the calendar year 2016, in the US census Populations.

\begin{tabular}{|c|c|c|}
\hline & \multicolumn{2}{|c|}{ Patients with OSA } \\
\hline Patient Characteristics & Database patients & Estimated \# in US population \\
\hline Demographics & & \\
\hline \# of patients & $2,576,429$ & $11,543,713$ \\
\hline Age, mean (years) & 58 & - \\
\hline Age, median (years) & 59 & - \\
\hline Age categories (years) & $2 \%$ & 223,828 \\
\hline$<18$ & $1 \%$ & 80,344 \\
\hline $18-24$ & $3 \%$ & 350,618 \\
\hline $25-34$ & $10 \%$ & $1,127,471$ \\
\hline $35-44$ & $20 \%$ & $2,339,587$ \\
\hline $45-54$ & $30 \%$ & $3,433,073$ \\
\hline $55-64$ & $35 \%$ & $3,988,791$ \\
\hline$\geq 65$ & & $6,615,924$ \\
\hline Sex & $57 \%$ & $4,927,789$ \\
\hline Male & $43 \%$ & \\
\hline Female & & \\
\hline
\end{tabular}


Gregory P. Hess et al.

\begin{tabular}{|c|c|c|}
\hline US Region & & \\
\hline Northeast & $19 \%$ & $2,209,115$ \\
\hline South & $25 \%$ & $2,879,018$ \\
\hline West & $38 \%$ & $4,396,114$ \\
\hline Midwest & $18 \%$ & $2,059,466$ \\
\hline Patients with $\geq 1$ medications to treat sleepiness ( $N=$ patients) & $6.5 \%$ & 752,327 \\
\hline Phosphodiesterase inhibitor ${ }^{1}$ dispensed $\mathrm{Rx}$ & & 55,204 \\
\hline Carbonic Anhydrase Inhibitor ${ }^{2}$ dispensed $\mathrm{Rx}$ & & 62,019 \\
\hline Antidepressive agent ${ }^{3}$ dispensed $\mathrm{Rx}$ & & 9,310 \\
\hline Modafinil or armodafinl dispensed Rx & & 244,116 \\
\hline Other central nervous system agent ${ }^{4}$ dispensed $\mathrm{Rx}$ & & 438,736 \\
\hline Patients with $\geq 1$ OSA treatments $(\mathrm{N}=$ patients) & $45.2 \%$ & $5,214,116$ \\
\hline PAP devices & & $5,093,895$ \\
\hline Oral Appliances & & 50,742 \\
\hline Upper Airway Surgical procedures & & 107,299 \\
\hline Hypoglossal Nerve Stimulation procedures & & 5,444 \\
\hline
\end{tabular}

Abbreviations: PAP, positive airway pressure; OSA, obstructive sleep apnea; US, United States.

1. Theophylline

2. Acetazolamide

3. Desipramine

4. Methylphenidate, Dextroamphetamine, Dexmethylphenidate Hydrochloride, Lisdexamfetamine Dimesylate

Table 4. Adjusted OSA Prevalence by Age, Sex, and Insurance Type to the 2016 US Census

\begin{tabular}{|c|c|c|c|c|c|c|c|}
\hline & $\begin{array}{c}\text { Study } \\
\text { Population }\end{array}$ & $\begin{array}{c}\text { Study } \\
\text { Patients with } \\
\text { OSA }\end{array}$ & $\begin{array}{c}\text { Study } \\
\text { Population }\end{array}$ & OSA & $\begin{array}{c}\text { \# OSA } \\
\text { Medicare } \\
\text { Prevalence }\end{array}$ & $\begin{array}{c}\text { \# OSA } \\
\text { Medicaid } \\
\text { Prevalence }\end{array}$ & $\begin{array}{c}\text { OSA All } \\
\text { Other } \\
\text { Prevalence } \\
\text { Prevalence }\end{array}$ \\
\hline Motal & $66,060,231$ & $2,576,429$ & $3.4 \% *$ & $3.5 \% *$ & $3.0 \% *$ & $2.7 \% *$ & $2.1 \%^{*}$ \\
\hline $\begin{array}{c}\text { All } \\
\text { ages }\end{array}$ & $26,126,600$ & $1,476,601$ & $4.8 \% * *$ & $4.9 \% * *$ & $3.4 \% * *$ & $3.1 \% * *$ & $2.7 \% \%^{* *}$ \\
\hline$<18$ & $4,736,097$ & 29,020 & $0.6 \%$ & $0.6 \%$ & $0.4 \%$ & $0.6 \%$ & $0.6 \%$ \\
\hline $18-24$ & $1,326,948$ & 9,798 & $0.7 \%$ & $0.7 \%$ & $1.4 \%$ & $0.9 \%$ & $0.4 \%$ \\
\hline $25-34$ & $1,513,938$ & 43,830 & $2.9 \%$ & $3.0 \%$ & $2.9 \%$ & $2.0 \%$ & $1.5 \%$ \\
\hline $35-44$ & $2,249,289$ & 153,043 & $6.8 \%$ & $7.0 \%$ & $4.8 \%$ & $4.3 \%$ & $3.4 \%$ \\
\hline $45-54$ & $3,481,277$ & 312,226 & $9.0 \%$ & $9.3 \%$ & $5.7 \%$ & $6.0 \%$ & $4.6 \%$ \\
\hline $55-64$ & $4,829,190$ & 427,021 & $8.8 \%$ & $9.2 \%$ & $5.5 \%$ & $5.6 \%$ & $4.7 \%$ \\
\hline$\geq 65$ & $7,989,861$ & 501,663 & $6.3 \%$ & $6.6 \%$ & $4.8 \%$ & $3.6 \%$ & $4.3 \%$ \\
\hline $\begin{array}{c}\text { Women } \\
\text { All }\end{array}$ & $39,933,631$ & $1,099,828$ & $2.2 \% * *$ & $2.2 \% * *$ & $2.7 \% * *$ & $2.3 \% * *$ & $1.5 \% * *$ \\
\hline
\end{tabular}




\begin{tabular}{|c|c|c|c|c|c|c|c|}
\hline$<18$ & $4,421,532$ & 20,936 & $0.5 \%$ & $0.5 \%$ & $0.3 \%$ & $0.5 \%$ & $0.5 \%$ \\
\hline $18-24$ & $2,790,515$ & 8,134 & $0.3 \%$ & $0.3 \%$ & $0.9 \%$ & $0.3 \%$ & $0.2 \%$ \\
\hline $25-34$ & $4,512,161$ & 34,424 & $0.8 \%$ & $0.8 \%$ & $2.0 \%$ & $0.8 \%$ & $0.5 \%$ \\
\hline $35-44$ & $4,731,196$ & 98,596 & $2.1 \%$ & $2.1 \%$ & $3.7 \%$ & $2.4 \%$ & $1.2 \%$ \\
\hline $45-54$ & $5,722,427$ & 209,944 & $3.7 \%$ & $3.6 \%$ & $4.8 \%$ & $4.7 \%$ & $2.3 \%$ \\
\hline $55-64$ & $6,878,861$ & 339,203 & $4.9 \%$ & $4.9 \%$ & $5.5 \%$ & $5.4 \%$ & $3.0 \%$ \\
\hline$\geq 65$ & $10,876,939$ & 388,591 & $3.6 \%$ & $3.8 \%$ & $2.8 \%$ & $2.9 \%$ & $3.0 \%$ \\
\hline
\end{tabular}

Abbreviations: OSA, obstructive sleep apnea.

*Age-and sex-adjusted to the 2016 census. **Age-adjusted to the 2016 US census. All other prevalences are unadjusted.

Regional variation was also observed with the highest prevalence in the West US Census region. The age- and sex- Census-adjusted prevalence of OSA increased from $2.4 \%$ in $2013,2.6 \%$ in 2014 , $3.0 \%$ in 2015, and 3.4\% in 2016 (Figure 1). Ageadjusted prevalences in 2016 for the insured were $4.7 \%$ per $100(95 \%$ CI $4.7,4.8)$ for males and $2.2 \%$ per 100 (95\% CI 2.2, 2.2) for females. Age- and sex-specific prevalences for 2016 multiplied by US census counts resulted in an estimate of 11.5 million nationwide cases in 2016 (Table 3, Table 4).

\section{Treatments Subgroups:}

PAP use was the most common therapeutic intervention, followed by upper airway surgery. The proportion of patients with PAP use increased from $42.2 \%$ to $44.1 \%$ over the study period. The proportion of patients with excessive sleepiness for patients with or without PAP use decreased over time by $4 \%$ - 5\%. A decline was seen in patients with OSA and PAP and evidence of excessive sleepiness from $20.9 \%$ in 2013 , to $19.5 \%$ in 2014 , to $18.2 \%$ in 2015 , and $15.8 \%$ in 2016 . A decrease was also seen in patients with OSA, no PAP use, and with excessive sleepiness declining from $18.7 \%$ in 2013 , to $17.3 \%$ in 2014 , to $16.0 \%$ in 2015 , and $14.1 \%$ in 2016 . Medications dispensed for excessive sleepiness (7\%) were generally classified as "other central nervous system agents" (i.e. stimulants e.g. methylphenidate, dextroamphetamine, methylphenidate, dexmethylphenidate hydrochloride, lisdexamfetamine dimesylate), followed by modafinil/armodafinil (Table 3).

\section{Discussion}

Within a large, geographically diverse population derived from a US healthcare claims database, our study found an increase in the annual prevalence of OSA over the period 2013 to 2016. Directly standardized to the 2016 Census Bureau estimates, the prevalence of OSA in the eligible insured population increased from $2.4 \%$ in 2013 to $3.4 \%$ in 2016, which projects to a 2016 nationwide count of approximately 11.5 million patients with OSA.

Our prevalence findings are within the lower range previously reported in other studies 13,14,21,22. This is due primarily to employing a the relatively short lookback period (2-year limited-duration prevalence) and requiring claims activity for cohort eligibility in order to focus on those actively seeking treatment. To assess the effect of a longer duration lookback we conducted a post hoc sensitivity analysis based on a 3-year period of available history. Adding an additional year of history increased the observed prevalence appreciably e.g. from $3.9 \%$ to $5.5 \%$ in 2016 . The appreciable difference between the 2-year and 3year limited duration prevalence suggests there is a substantial portion of patients who were diagnosed with OSA but are no longer being seen for the condition. While the reasons are likely multi-factorial, studies commonly report that two thirds to a half of patients discontinue PAP, a mainstay of therapy, within 3 years 23,24,25,26,27 and fail to follow up. Quoting the Awake Report, Patient-focused Product Development for OSA, "For patients with OSA, 
the treatment can be as bothersome as the disorder." 28,29,30,31 The approximate 2:1 male to female prevalence ratio we found was similar to sex ratios reported in other studies. The variation in findings between the present study and previous US-based 14 and international studies 13,15,16 likely reflects a combination of lookback period length, cohort definition (viz., those with medical and prescription claims), case definition, and population characteristics, as well as changes in the diagnostic testing and clinical criteria used to define OSA.32,33,34,35.

Understanding the determinants of the increasing prevalence is beyond the scope of this descriptive study. 36 Studies have repeatedly found that OSA is undiagnosed, 37,38,39, and an increase in awareness and diagnosis of the condition may be a contributing factor to the increase in prevalence of diagnosed disease. Obesity is a wellknown risk factor for OSA6, 40,41 and the increase in body mass index in the general population may be a significant driver. 42 other reported risk factors include older age, male sex, menopause, anatomic abnormalities, and family history. OSA risk is also increased in association with a range of comorbid and concomitant medical conditions including pregnancy, end-stage renal disease, diabetes, congestive heart failure, chronic lung disease, post-traumatic stress disorder, and stroke.

Excessive sleepiness may persist in patients with OSA, despite PAP use. However, whether OSA is the direct cause of or a risk factor for excessive sleepiness is unknown, and other mechanisms such as obesity and snoring may account for sleepiness. 43,44 additionally, other factors may come into play, such as inadequate PAP adherence and/or treatment, the lack of a clear definition of excessive sleepiness, and undiagnosed associated conditions such as depression or narcolepsy. 43,44 The observed frequency of recorded diagnoses may also increase or decrease in claims data over time in response to billing and reimbursement policies. 45 Our study found that in 2016, excessive sleepiness occurred in $15.8 \%$ of patients with OSA plus PAP use, and in $14.1 \%$ of patients with OSA and no PAP use.

For males, diagnosed OSA prevalence generally appeared to be higher in those with commercial insurance, while females with Medicare generally had a higher prevalence. This observed association may be artifactual or related to characteristics of this sub-population, e.g. greater persistency or better coverage (Table 2). As discussed previously, variations exist in the testing, criteria and subsequent diagnosis of OSA. Definitions of disease may vary based on the payer's criteria for diagnosis, e.g. apnea-hypopnea index minimum qualification for PAP use. These variations likely carry over to differences observed in payer's policies and the 10,000 plus estimated health plans in the US. 46

There are advantages and disadvantages to our approach of using medical and pharmacy claims to study OSA prevalence and treatment patterns. The most obvious advantage is the ability to base our analyses on more than 66 million individuals with appreciable geographic representation in all 50 states. That enabled estimates of prevalence and treatment patterns of high statistical precision for subgroups defined by year, sex, age, type of insurance, and region of the country. The major disadvantage of our claims-based approach is the inability to confirm diagnoses for OSA patients with clinical information. To mitigate that disadvantage, we used an algorithm that required 2 OSA claims within a 6-month period. This approach has been used widely with claims data to obviate rule-out diagnoses and has been found to identify cases with a high positive predictive value. The tradeoff is some loss of sensitivity. So, our case identification should be interpreted to be focused on those with active disease or actively seeking care, the population of interest for assessing treatment patterns over time. Other limitations include that the experience of insured patients may differ from that of uninsured patients and that the Medicare patients in our dataset were largely those enrolled in Medicare Advantage plans, considered to be a healthier subset of the Medicare population. Finally, PAP use may be under-reported as durable medical equipment claims are not always captured through pharmacy or private practitioner medical claims. On balance, however, our analysis of claims data likely provides a valid assessment that 
OSA prevalence and PAP usage increased over the 2013-2016 time period, that prevalence was higher for males than for females, and that clinical markers of excessive sleepiness declined. These trends are informative for clinicians, payers, and patients and highlight the growing significance of OSA and the need for continued progress in treating these patients.

\section{Acknowledgments:}

The authors appreciate the assistance of Anna Fievitz, Eugene Fievitz, Olga Pasenchenko, Sean Redmond, and Kathleen Villa.

Author Contributions: Dr. Hess was the primary investigator and responsible for the integrity of the study as well as the final content of the manuscript. Dr. Acquavella contributed substantially to the study design, data analysis and interpretation, and the writing of the manuscript. Drs. Won, Bron, and Ms. Suomi contributed to the study design, interpretation of results and writing of the manuscript. Each author reviewed and gave full approval for the contents of the manuscript.

Financial/nonfinancial disclosures: Mr. Hess, Mr. Acquavella, Ms. Won, and Ms. Suomi served as an employee or contractor to Symphony Health, which received research funding from Jazz pharmaceuticals. They have no other relevant conflicts of interest to disclose.

Ms. Bron was an employee of Jazz Pharmaceuticals, and holds stock and/or stock options in Jazz Pharmaceuticals, plc.

Role of the sponsor: Ms. Bron provided input to the design of the study, and interpretation of findings. The sponsor reviewed the manuscript and provided comments for consideration by the authors. However final decisions on the content of the manuscript were determined by the academic authors.

\section{References:}

1. Pang KP, Terris DJ. Screening for obstructive sleep apnea: an evidence-based analysis. Am J Otolaryngol. 2006;27(2):112-8.

2. Hiestand DM, Britz P, Goldman M, Phillips
B. Prevalence of symptoms and risk of sleep apnea in the US population: Results from the national sleep foundation sleep in America 2005 poll. Chest. 2006;130(3):780-6.

3. Section on Pediatric Pulmonology SboOSASAAoP. Clinical practice guideline: diagnosis and management of childhood obstructive sleep apnea syndrome. Pediatrics. 2002;109(4):704-12.

4. Kapoor M, Greenough G. Home Sleep Tests for Obstructive Sleep Apnea (OSA). J Am 296 Board Fam Med. 2015;28(4):504-9.

5. Netzer NC, Hoegel JJ, Loube D, Netzer CM, Hay B, Alvarez-Sala R, et al. Prevalence of symptoms and risk of sleep apnea in primary care. Chest. 2003;124(4):1406-14.

6. Jordan AS, McSharry DG, Malhotra A. Adult obstructive sleep apnoea. Lancet. 2014;383(9918):736-47.

7. Cepeda-Valery B, Acharjee S, RomeroCorral A, Pressman GS, Gami AS. Obstructive sleep apnea and acute coronary syndromes: etiology, risk, and management. Curr Cardiol Rep. 2014;16(10):535.

8. Sidhu K, Tang A. Modifiable Risk Factors in Atrial Fibrillation: The Role of Alcohol, Obesity, and Sleep Apnea. Can J Cardiol. 2017;33(7):947-9.

9. Mohsenin V. Obstructive sleep apnea and hypertension: a critical review. Curr Hypertens 307 Rep. 2014;16(10):482.

10. Lin CC, Hu CC, Ho JD, Chiu HW, Lin HC. Obstructive sleep apnea and increased risk of glaucoma: a population-based matchedcohort study. Ophthalmology. 2013;120(8):1559-64.

11. Zhao Y, Yu BY, Liu Y. Meta-Analysis of the Effect of Obstructive Sleep Apnea on Cardiovascular Events After Percutaneous Coronary Intervention. Am J Cardiol. 2017;120(6):1026-30.

12. Rosen CL, Debaun MR, Strunk RC, Redline S, Seicean S, Craven DI, et al. 
Obstructive sleep apnea and sickle cell anemia. Pediatrics. 2014;134(2):273-81.

13. Punjabi NM. The epidemiology of adult obstructive sleep apnea. Proc Am Thorac Soc. 2008;5(2):136-43.

14. Peppard PE, Young T, Barnet JH, Palta M, Hagen EW, Hla KM. Increased prevalence of sleep-disordered breathing in adults. Am J Epidemiol. 2013;177(9):1006-14.

15. Heinzer R, Vat $S$, Marques-Vidal P, MartiSoler H, Andries D, Tobback N, et al. Prevalence of sleep-disordered breathing in the general population: the HypnoLaus study. Lancet Respir Med. 2015;3(4):3108.

16. Senaratna CV, Perret JL, Lodge CJ, Lowe AJ, Campbell BE, Matheson MC, et al. Prevalence of obstructive sleep apnea in the general population: A systematic review. Sleep Med Rev. 2017;34:70-81.

17. Grosse SD, Boulet SL, Grant AM, Hulihan MM, Faughnan ME. The use of US health insurance data for surveillance of rare disorders: hereditary hemorrhagic telangiectasia. Genet Med. 2014;16(1):339.

18. Fukuda H, Ikeda S, Shiroiwa T, Fukuda T. The Effects of Diagnostic Definitions in Claims Data on Healthcare Cost Estimates: Evidence from a Large-Scale Panel Data Analysis of Diabetes Care in Japan. Pharmacoeconomics. 2016;34(10):100514.

19. Tanihara S, Okamoto E, Une H. A statistical analysis of 'rule-out' diagnoses in outpatient health insurance claims in Japan. J Eval Clin Pract. 2011;17(6):1070-4.

20. Newcombe RG. Two-sided confidence intervals for the single proportion: comparison of seven methods. Stat Med. 1998;17(8):857-72.

21. Young T, Palta M, Dempsey J, Skatrud J, Weber S, Badr S. The occurrence of sleep-disordered breathing among middleaged adults. $\mathrm{N}$ Engl J Med. 1993;328(17):1230-5.

22. Myers KA, Mrkobrada M, Simel DL. Does this patient have obstructive sleep apnea?:
The Rational Clinical Examination systematic review. JAMA. 2013;310(7):731-41.

23. Baratta F, Pastori D, Bucci T, Fabiani M, Fabiani V, Brunori M, et al. Long-term prediction of adherence to continuous positive air pressure therapy for the treatment of moderate/severe obstructive sleep apnea syndrome. Sleep Med. 2018;43:66-70.

24. Wolkove N, Baltzan M, Kamel H, Dabrusin R, Palayew M. Long-term compliance with continuous positive airway pressure in patients with obstructive sleep apnea. Can Respir J. 2008;15(7):3659.

25. Sin DD, Mayers I, Man GC, Pawluk L. Long-term compliance rates to continuous positive airway pressure in obstructive sleep apnea: a population-based study. Chest. 2002;121(2):430-5.

26. Weaver TE, Grunstein RR. Adherence to continuous positive airway pressure therapy: the challenge to effective treatment. Proc Am Thorac Soc. 2008;5(2):173-8.

27. Wozniak DR, Lasserson TJ, Smith I. Educational, supportive and behavioural interventions to improve usage of continuous positive airway pressure machines in adults with obstructive sleep apnoea. Cochrane Database Syst Rev. 2014(1):CD007736.

28. Association ASA. Awake. Sleep Apnea.; 2018.

29. Broström A, Nilsen P, Johansson P, Ulander M, Strömberg A, Svanborg E, et al. Putative facilitators and barriers for adherence to CPAP treatment in patients with obstructive sleep apnea syndrome: a qualitative content analysis. Sleep Med. 2010;11(2):126-30.

30. Olsen S, Smith S, Oei T, Douglas J. Health belief model predicts adherence to CPAP before experience with CPAP. Eur Respir J. 2008;32(3):710-7.

31. Sawyer AM, Gooneratne NS, Marcus CL, Ofer D, Richards KC, Weaver TE. A 
systematic review of CPAP adherence across age groups: clinical and empiric insights for developing CPAP adherence interventions. Sleep Med Rev. 2011;15(6):343-56.

32. Won CHJ, Qin L, Selim B, Yaggi HK. Varying Hypopnea Definitions Affect Obstructive Sleep Apnea Severity Classification and Association With Cardiovascular Disease. J Clin Sleep 363 Med. 2018;14(12):1987-94.

33. Malhotra RK, Kirsch DB, Kristo DA, Olson EJ, Aurora RN, Carden KA, et al. Polysomnography for Obstructive Sleep Apnea Should Include Arousal-Based Scoring: An American Academy of Sleep Medicine Position Statement. J Clin Sleep Med. 2018;14(7):1245-7.

34. Ruehland WR, Rochford PD, O'Donoghue FJ, Pierce RJ, Singh P, Thornton AT. The new AASM criteria for scoring hypopneas: impact on the apnea hypopnea index. Sleep.2009;32(2):150-7.

35. Mansukhani MP, Kolla BP, Wang Z, Morgenthaler TI. Effect of Varying Definitions of Hypopnea on the Diagnosis and Clinical Outcomes of Sleep-Disordered Breathing: A Systematic Review and MetaAnalysis. J Clin Sleep Med. 2019;15(5):687-96.

36. Young T, Skatrud J, Peppard PE. Risk factors for obstructive sleep apnea in adults. JAMA. 2004;291(16):2013-6.

37. Finkel KJ, Searleman AC, Tymkew H, Tanaka CY, Saager L, Safer-Zadeh E, et al. Prevalence of undiagnosed obstructive sleep apnea among adult surgical patients in an academic medical center. Sleep Med. 2009;10(7):753-8.

38. Devaraj U, Rajagopala S, Kumar A, Ramachandran P, Devereaux PJ, D'Souza GA. Undiagnosed Obstructive Sleep Apnea and Postoperative Outcomes: A Prospective
Observational 380 Study. Respiration. 2017;94(1):18-25.

39. Lang CJ, Appleton SL, Vakulin A, McEvoy RD, Vincent AD, Wittert GA, et al. Associations of Undiagnosed Obstructive Sleep Apnea and Excessive Daytime Sleepiness With Depression: An Australian Population Study. J Clin Sleep Med. 2017;13(4):575-82.

40. Hamilton GS, Joosten SA. Obstructive sleep apnoea and obesity. Aust Fam Physician. 2017;46(7):460-3.

41. Romero-Corral A, Caples SM, LopezJimenez F, Somers VK. Interactions between obesity and obstructive sleep apnea: implications for treatment. Chest. 2010;137(3):711-9.

42. Peppard PE, Young T, Palta M, Dempsey J, Skatrud J. Longitudinal study of moderate weight change and sleepdisordered breathing. JAMA. 2000;284(23):3015-21.

43. Santamaria J, Iranzo A, Ma Montserrat J, de Pablo J. Persistent sleepiness in CPAP treated obstructive sleep apnea patients: evaluation and treatment. Sleep Med Rev. 2007;11(3):195-207.

44. Castiglioni P, Lombardi C, Cortelli P, Parati G. Why excessive sleepiness may persist in OSA patients receiving adequate CPAP treatment. Eur Respir J. 2012;39(1):226-7; author reply 7-8.

45. Thorpe KE, Florence CS, Howard DH, Joski P. The rising prevalence of treated disease: effects on private health insurance spending. Health Aff (Millwood). 2005;Suppl Web Exclusives:W5-317-W525.

46. Thomas RJ, Guilleminault C, Ayappa I, Rapoport DM. Scoring respiratory events in sleep medicine: who is the driver--biology or medical insurance? J Clin Sleep Med. 2014;10(11):1245- 7. 